\title{
Assessment of mechanical characteristics of steel subject to cyclic loads effect on non- standard compact specimens
}

\author{
Rim N. Khasanov ${ }^{1}$, Aybulat S. Valiev ${ }^{1, *}$, and Iskander R. Kuzeev ${ }^{1}$ \\ ${ }^{1}$ FSBEI of Higher Education "Ufa State Petroleum Technological University" \\ Ufa, the Russian Federation
}

\begin{abstract}
It is showed by experiments that the use of compact specimens for determination of fracture work of steel that undertook cyclic deformations enables to identify metal with a number of cumulative fatigue damages. The yield limit determined in the first series of experiments was used for cycling parameters determination: 0.9 from the yield limit was set for damage accumulation in the elastoplastic stress range. At the same time an average cycle load was $8.9 \mathrm{kN}$, and an amplitude was $8.6 \mathrm{kN}$. It is demonstrated that specific fracture work increases upon the increase of compact specimens' thickness. The tendency of specific fracture work decrease is observed upon fatigue damage accumulation. Thin specimens are particularly sensitive to damage accumulation. The results of the experiments indirectly support the hypothesis of fractional-dimensional surface layer existence.
\end{abstract}

\section{Introduction}

The correlation between steel mechanical characteristics (as exemplified by the yield limit and fracture work) determined by the standard method and with the use of compact specimens was obtained in the first part of our report $\left({ }^{* *}\right)$.

The use of compact specimens for determination of constructional materials mechanical properties proved their efficiency under a limited amount of basic material $[1-3,8]$ and methods of their operation are improving [4-7].

\section{Experimental procedure. Statistical tests}

An attempt of mechanical characteristics change assessment upon fatigue damage accumulation was made during the next step of the researches. Cyclic tests were conducted on Instron 8801 servohydraulic testing machine with the use of cylindrical specimens dimensions of which corresponded to the specimens used for statistical tests. The yield limit determined in the first series of tests was used for cycling parameters determination:

\footnotetext{
* Corresponding author: valiev16101994@yandex.ru
} 
0.9 from the yield limit was set for damage accumulation in the elastoplastic stress range. At the same time an average cycle load was $8.9 \mathrm{kN}$, and an amplitude was $8.6 \mathrm{kN}$ as shown in Fig.1. This enabled to realize during the tests so-called "zero-based" cycling principle when plastic tension deformations are accumulated one-sidedly in the specimens. The specimens were loaded by fixed amount of cycles: $3 \times 10^{4}, 6 \times 10^{4}, 9 \times 10^{4}, 13,6 \times 10^{4}$ cycles.

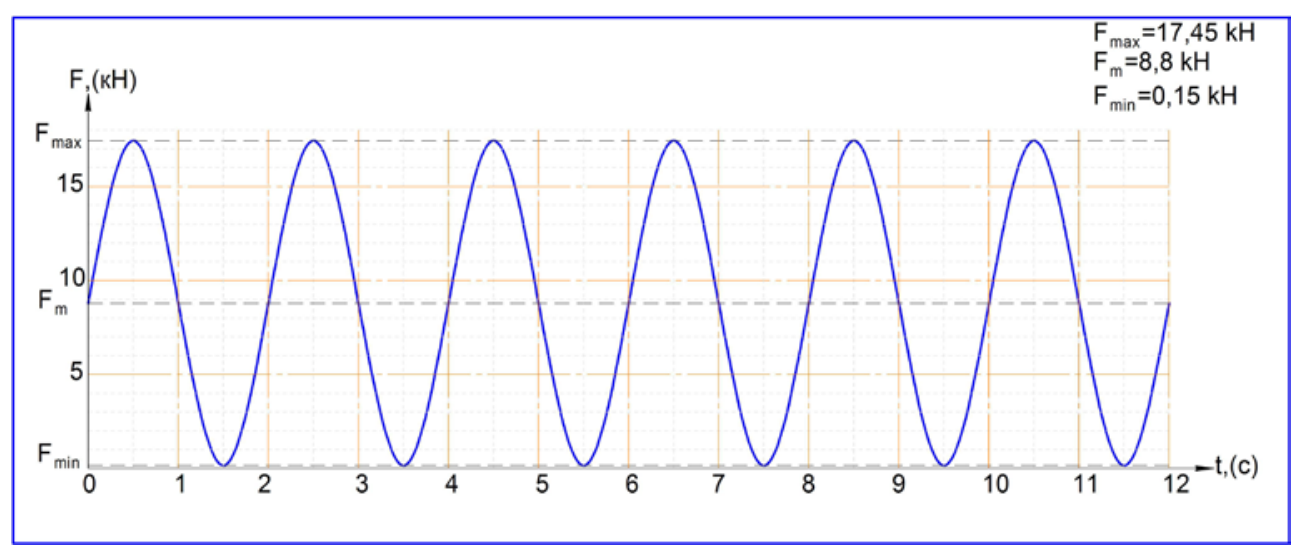

Fig. 1. Sine-shaped diagram for zero-based cycle.

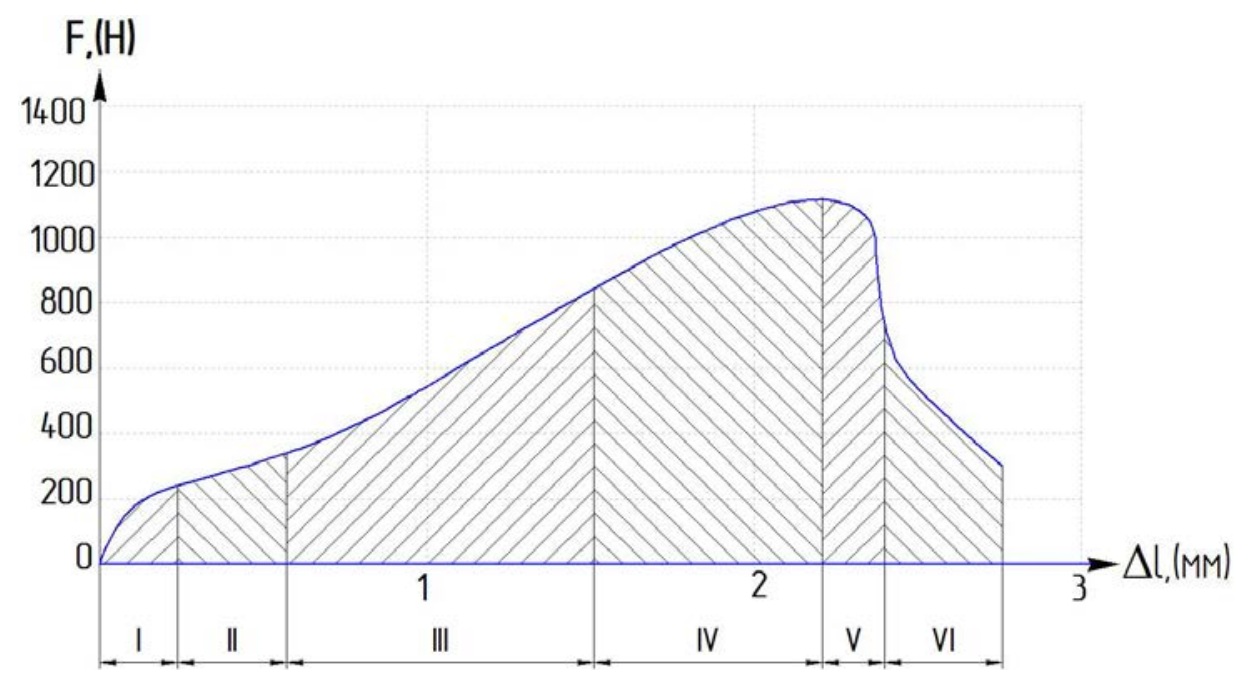

Fig. 2. Standard tension diagram zones obtained by SPT-method.

Standard diagrams obtained by SPT-method (Fig.2) which were divided into the following zones were used for the analysis: I (elastic deformation), II (elastoplastic transition), III (plastic deformation), IV (formation and extension of microcracks), V (fractures softening zone) and VI (final fracture).

Let us analyse comparative diagrams of initial undeformed specimens and microspecimens cycled as per maximum amount of cycles $13,6 \times 10^{4}$ that were used in our experiments, that were cut into compact specimens (Fig.3). 
a

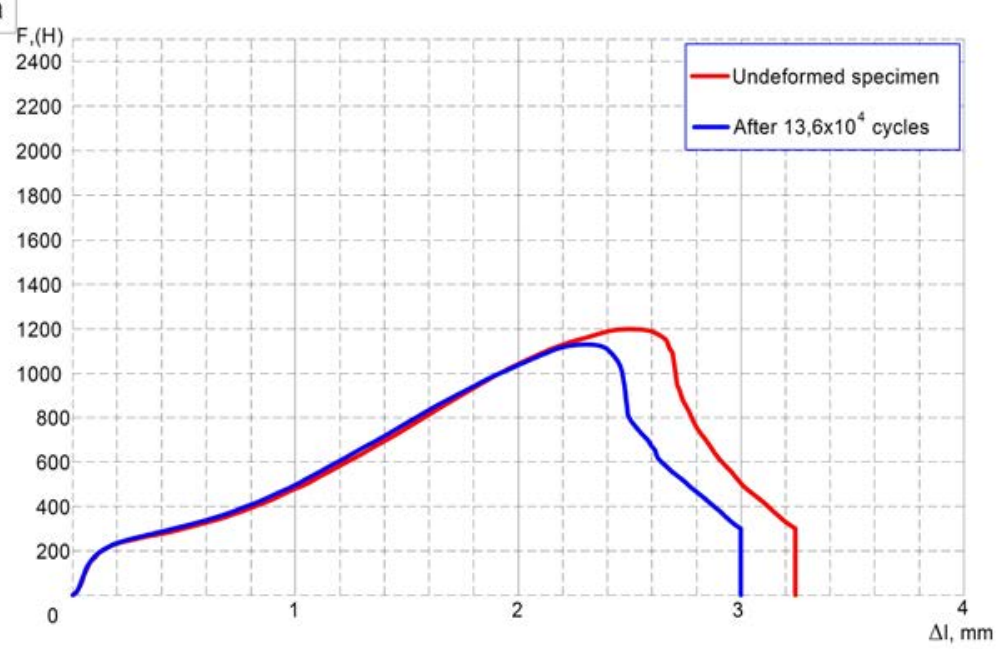

b

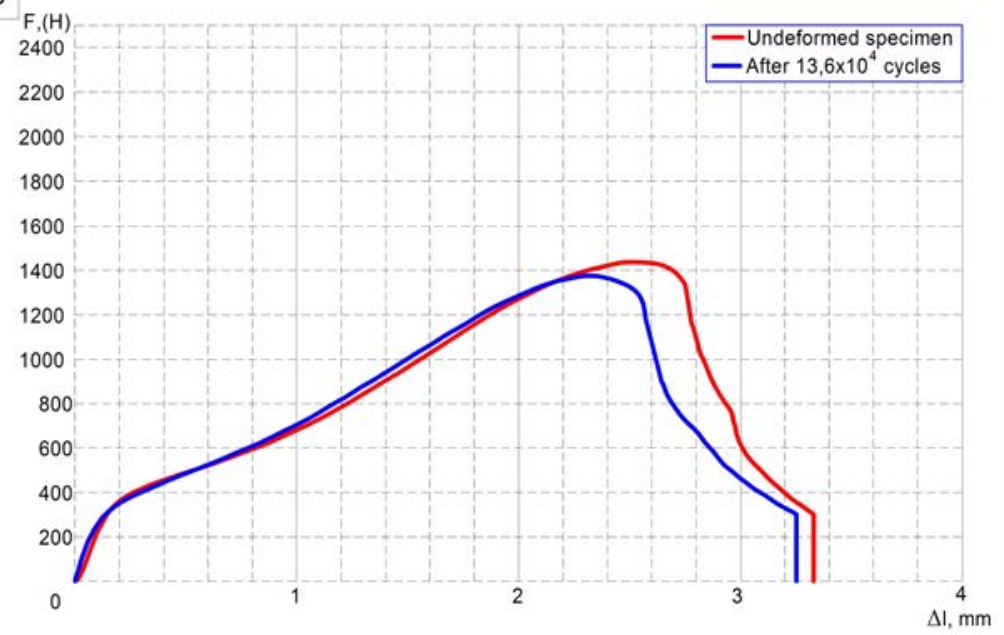

C

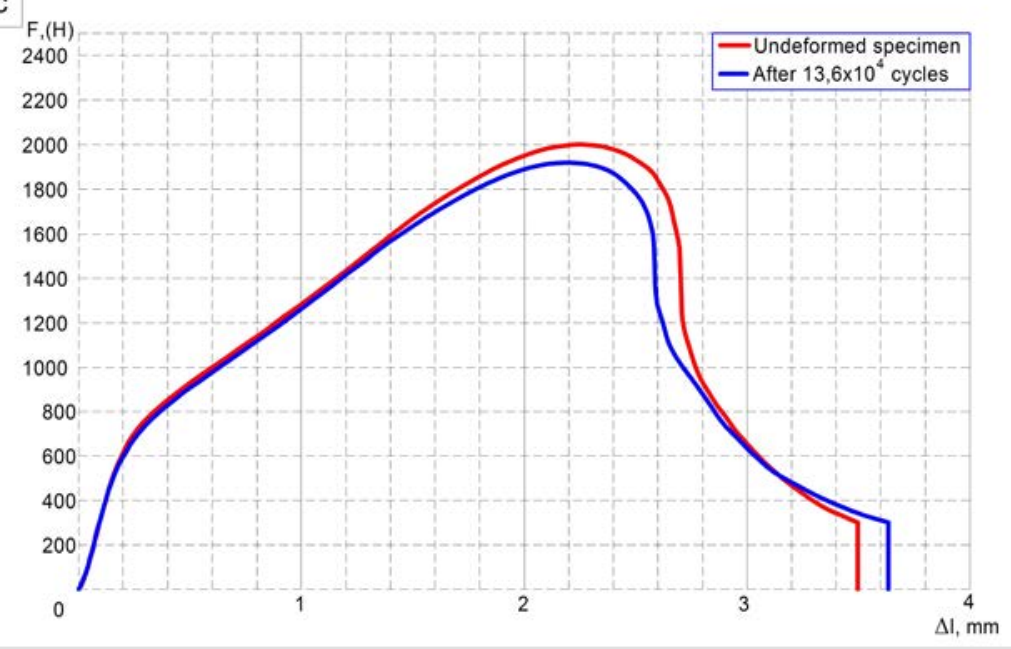




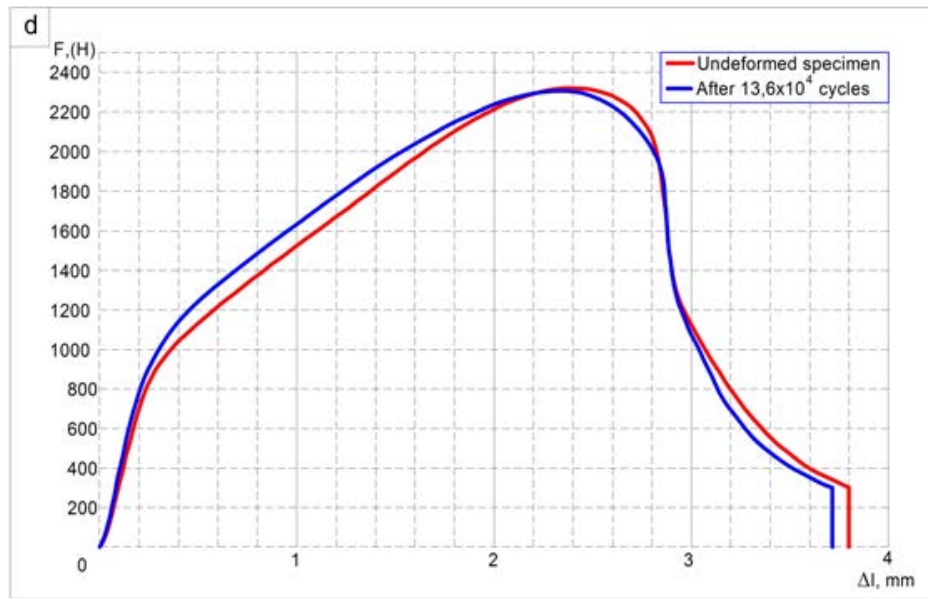

Fig. 3. Tension diagrams of compact samples of different thickness obtained after cyclic tension test $\left(13,6 \times 10^{4}\right.$ cycles $)$ of standard cylindrical specimens, $\mathrm{mm}$ : a - 0,6; b - 0,8; c - 1,0; $\mathrm{d}-1,2$.

Analysis of the obtained diagrams enables to make several conclusions. Within the hypothesis of fractional-dimensional surface layer existence in solid bodies [9] one can state the possible influence of the layer on fracture process of specimens thickness of which is less than $1 \mathrm{~mm}$. Specific fracture work increases upon the increase of compact specimens' thickness. The tendency of specific fracture work decrease is observed upon fatigue damage accumulation. Thin specimens are particularly sensitive to damage accumulation. Authors associate this fact with availability of fractional-dimensional surface layer [9].

According to fracture diagrams one can evaluate expenses for separate fracture stages in compliance with Fig. 2:

$$
\begin{gathered}
A_{\text {makcrocrack }}=A_{I}+A_{I I}+A_{I I I}+A_{I V} \\
A_{\text {fracture }}=A_{I}+A_{I I}+A_{I I I}+A_{I V}+A_{V} \\
A_{\text {full fracture }}=A_{I}+A_{I I}+A_{I I I}+A_{I V}+A_{V}+A_{V I}
\end{gathered}
$$

being $A_{I}, A_{I I}, A_{I I I}, A_{I V}, A_{V}, A_{V I}-$ works of the corresponding fracture diagram zones.

Comparative data was obtained for analysis, besides fracture work values were divided by area that was calculated as multiplication of indenter diameter with compact specimen

\begin{tabular}{|c|c|c|c|c|c|c|}
\hline \multirow{3}{*}{ Type of work } & \multirow{3}{*}{$\begin{array}{c}\text { Thickness } \\
\text { of } \\
\text { specimens }\end{array}$} & \multicolumn{5}{|c|}{ Amount of cycles (thousands) } \\
\hline & & $\mathbf{0}$ & 30 & 52 & 90 & 136 \\
\hline & & \multicolumn{5}{|c|}{ Relative works $(\mathrm{H} / \mathrm{mm})$} \\
\hline \multirow{3}{*}{$\begin{array}{l}\text { Macrocrack } \\
\text { formation }\end{array}$} & 0.6 & 1358.75 & 1242.54 & 1153.31 & 1085.98 & 1216.5 \\
\hline & 0.8 & 1331.38 & 1349.42 & 1249.5 & 1357.81 & 1219.44 \\
\hline & 1 & 1518.6 & 1476.38 & 1315 & 1467.12 & 1435.43 \\
\hline \multirow{3}{*}{ Fracture } & 0.6 & 1561.5 & 1439.5 & 1385.92 & 1226.81 & 1358.27 \\
\hline & 0.8 & 1672.63 & 1630.61 & 1535.31 & 1615.98 & 1376.69 \\
\hline & 1 & 1891.05 & 1951.98 & 1683.55 & 1806.25 & 1831.63 \\
\hline \multirow{3}{*}{$\begin{array}{l}\text { Fracture with } \\
\text { crack opening }\end{array}$} & 0.6 & 1807.5 & 1579.75 & 1606.75 & 1413.5 & 1614.31 \\
\hline & 0.8 & 1779.19 & 1815.91 & 1776.71 & 1816.89 & 1647.28 \\
\hline & 1 & 2111.1 & 2064.83 & 1905.53 & 2009.88 & 2124.65 \\
\hline
\end{tabular}
thickness. Results are indicated in the table 1.

Table 1. Values of relative work of macrocrack formation, fracture and complete operation 
For illustrative purposes the obtained variations of the specific fracture work with respect to the amount of load cycles are shown in Fig. 4-6. This is the way the sensitivity of SPT method for assessment of cumulative fatigue damages level in constructions as well as upon determination of causes of equipment accidents is shown.

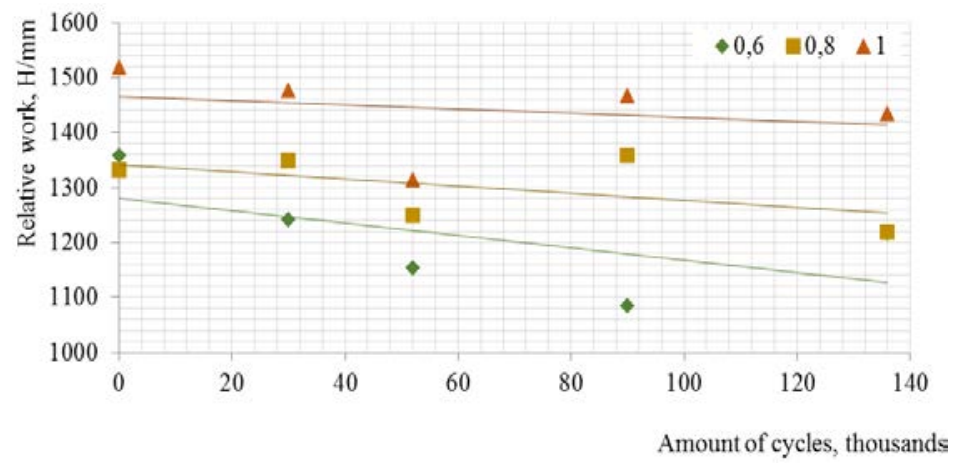

Fig. 4. Variations of relative work of macrocracks formation with the respect to the amount of cycles for specimens of different thickness.

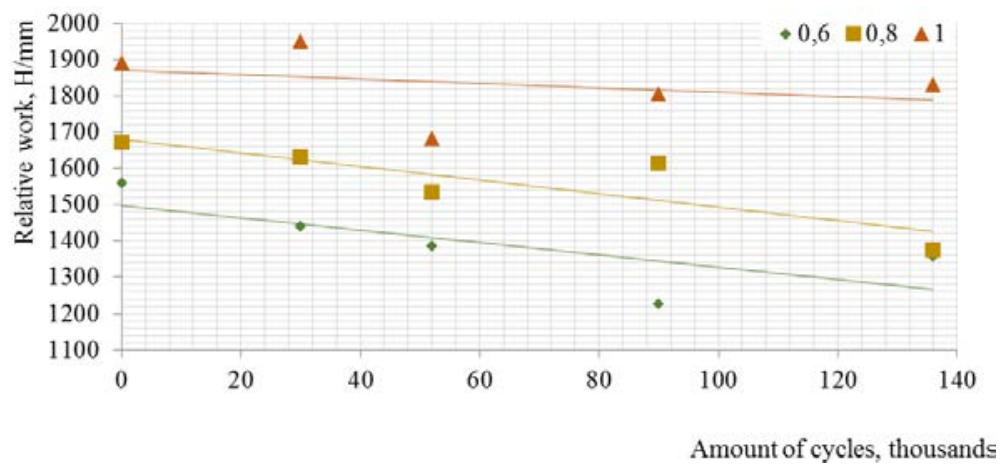

Fig. 5. Variations of relative fracture work with the respect to the amount of cycles for specimens of different thickness.

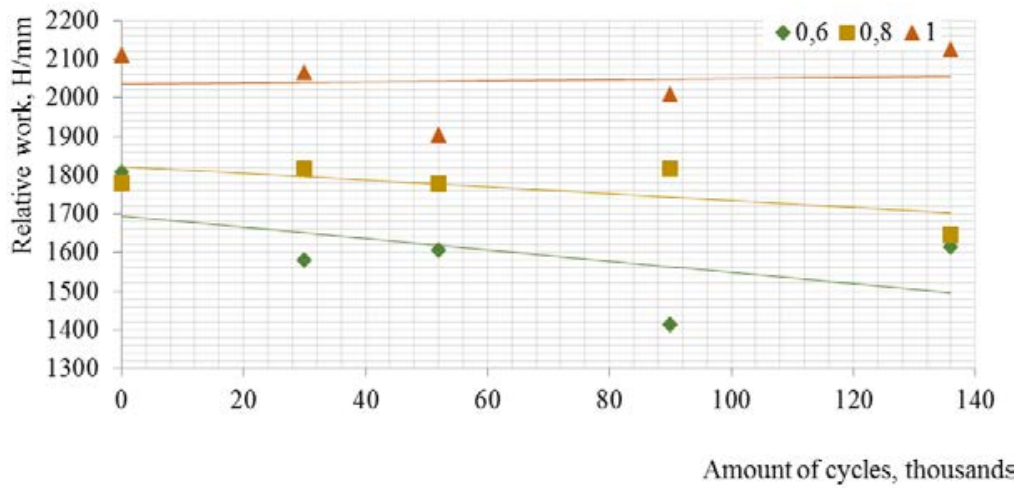

Fig. 6. Variations of full relative fracture work with the respect to the amount of cycles for specimens of different thickness. 


\section{Conclusions}

The experiments enabled to determine variations of relative fracture work of compact specimens with the respect to the amount of cumulative damages upon cyclic load of metal that enables to assess the level of cumulative damages according to the compact specimens test results. While using compact specimens for cumulative damages assessment it is necessary to take into account the fact that the specific fracture work decreases upon the decrease of test specimens' thickness.

\section{References}

1. R.N. Khasanov, Use of compact specimens for determination of constructional materials mechanical properties, USPTU young scientist bulletin, №1, pp. 5-11 (2016)

2. R.N. Khasanov, V.A. Gafarova, M.R. Abdulganiev, I.R. Kuzeev, Assessment of mechanical properties of constructional materials with the use of compact specimens, Modern methods and tools of diagnostics of electric and electrotechnical equipment, automation means and systems; materials of Russian National Science and Technology Conference, pp. 268-269 (2016)

3. R.N. Khasanov, A.A. Ryabov, I.R. Kuzeev, Dete rmination of fracture work on compact steel specimens, Problems of gathering, processing and transportation of crude oil and petroleum products, E 1 (107), pp. 116-123 (2017)

4. R.V. Khertsberg, Deformation and fracture mechanics of constructional materials (Metallurgiya, 1989)

5. B.A. Drozdovskiy, T.V. Polishchuk, V.P. Volkov, Chevron notch as a tool for specimen thickness decrement upon determination of Klc value, Plant laboratory, №6. pp. 74-76 (1987)

6. L.M. Barker, F. I. Baratta, Comparisons of Fracture Toughness Measurementsby the Short Rod and ASTM Standard Method of Test for Plane-Strain FractureToughness of Metallic Materials, E 399-78, Journal of Testing and Evaluation, Vol. 8, pp. 97-102 (1980)

7. American Society for Testing and Materials. Standard Test Method for PlainStrain (Chevron-Notch) Fracture Toughness of Metallic Materials, E 1304-97 (Annual book of standards, Philadelfia, 2005)

8. A.S. Solyanik, K.V. Shchedrivyy, Methodology of determination of fracture resistance characteristics of metal plates and covers of small thickness, Tomsk Polytechnic University bulletin, V.309, № 4, pp.136-140 (2006)

9. I.R. Kuzeev, Ye.A. Naumkin, Yu.N. Savicheva, S.V. Popova, Surface and surface phenomena, Neftegazovoye delo" publishing house, p.144 (2008) 